\title{
Crochet - a knowhow of cultural heritage: tradition, handcrafts, and income generation
}

\author{
Bianca Xavier Lemes ${ }^{1, a}$, Andréa Franco Pereira ${ }^{1}$ \\ ${ }^{1}$ Universidade Federal de Minas Gerais, Department of Architectural and Urban Technology, Rua Paraiba, 697, Belo Horizonte, Brazil
}

\begin{abstract}
This paper presents the development of a Master's degree research project, which deals with the trade of crochet and the values relate to the knowhow of the artificer, focusing on the work of women crocheters from the southern regions of the state of Minas Gerais, Brazil. Assuming the principle that the valuation of the knowhow of a community contributes to the continuance of the tradition; to the construction of identity and the affirmation of subject and culture; as well as to the valuation of the product stemming from this trade, this study seeks to investigate in what way this knowhow can add value to a group of craftswomen from the southern regions of Minas Gerais. This investigation is presented as an action research, given that the researcher, herself a crocheter, brings with her the knowhow of a group of craftswomen with whom she has established partnerships in the production and commercialization of crochet pieces. A bibliographic survey was conducted regarding this knowhow in the spheres of intangible heritage and of this group of women, focusing on the handcrafts, on the tradition, on the feminine, and on the meeting. Data collection performed in the field was conducted through semi-structured interviews directed at this group of crochet craftswomen. The partial results obtained illustrate the importance of the meetings among these women, favoring the exchange of knowledge and the continuance of the tradition, as well as the economic aspects related to income generation through the trade of these handcrafts.
\end{abstract}

Keywords. Knowhow; Intangible heritage; Craftswoman; Crochet; Handcrafts.

\section{Introduction}

The present study deals with the crochet trade and the values related to the knowhow of the artificer through the lens of tangible and intangible heritage. This making of handcrafts, passed down through the family tradition, is still alive today, bringing with it the processes of this handcraft built through the memory and everyday life of a specific group of women. Seeking to add value to this knowhow, It is proposed a reflection on crochet, woven by a group of women crocheters, in order to make it feasible to create a final product with the intention of generating income, thus boosting the economic, cultural, and social development of the group, as well as adding value to the heritage itself.

Within the production of handcrafts in the Minas Gerais cities of Campanha and Três Corações, we came across a strong, though anonymous, presence within the households of these cities - women who have been working with the crochet trade for years, passed down by their mothers, grandmothers, and aunts. The crochet produced by these women is sold in these cities as handcrafts in the form of bedspreads and household decorations. Another specific group of women uses their trade in the manufacture and commercialization of clothing.

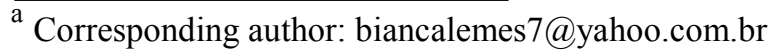

Taking this into account, some guiding questions were formulated for this study: In which social and economic contexts can these craftswomen be found in their local community? What is the role of the woman in the transference of the crochet craft? What are the social and cultural conceptions present in the meeting of a women's circle to do crochet? Does crochet, as a handcraft, generate local development? What legacies, from the point of view of heritage, could this knowledge leave to the community?

The main underlying methodological references for the present study can be found in the works of Raymond Quivy and Luc Van Campenhoudt about a social sciences investigation manual and Michel Thiollent concerning the action research methodology.

\section{Intangible heritage and knowhow}

In recent decades, the term heritage has been contemplating a wide range of knowledge from the most diverse of fields, thus expanding the realm of new agents and mechanisms of knowledge for its analysis. Thinking about the heritage of a community also means taking into consideration a wide range of cultural, social, and economic aspects, in addition to its environmental and ecological benefits and impacts. 
The Brazilian Federal Constitution of 1988, in articles 215 and 216, incorporated the broadening of the term heritage, referring to tangible and intangible goods.

According to Castriota (2009, p.207), in this same period, in 1989, UNESCO ${ }^{1}$ established the "Recommendation on the Safeguarding of Traditional Culture and Folklore." Decree $5.753^{2}$ defines that "Intangible Cultural Heritage" is constantly recreated by the communities by being handed down from generation to generation through the environment and interactions, in turn generating a sense of identify and continuity while promoting cultural diversity.

Hence, as they are constantly recreated, the intangible cultural goods are vulnerable due to the constant mutations and transformation inherent to society and to its citizens. In this sense, Castriota (2009, p.39) points out that "in the modern world, the logic of culture becomes that of change itself, of the incessant substitution of values and models". Within this change arises the need to think of the preservation of tradition in its "dynamic sphere", which characterizes modernity.

In this manner, adding value to the "knowhow" of craftswomen in the crochet craft makes it possible to strengthen the values and identity of the group of women, making it interesting to know who each woman is and how they interact with one another and with the community through their crochet knowhow. According to Hall (2005, p.12), social identity "would project ourselves in other identities" at the same time that it would lead us to internalize its "values and meanings", making them "part of us".

The "knowhow" of the craft may well affirm the identity of a given group of craftswomen with, as well as of their references to, the intangible good, which is the action itself by means of manual and exclusive production, with a local, social, historical, and cultural character, which is also in constant change, according to the time period in which we live.

\section{Handcrafts - Manual skill and valuation}

The crafts are linked to the handcraft skills, to the figure of the artificer or craftsman, in the realm of the work called handcrafts. Regarding the craftsman, Sennett (2015) points out that his celebration has long been found in a Homeric Hephaestus hymn ${ }^{3}$, in which the craftsman would be the generator of peace, one who

\footnotetext{
1 - UNESCO- United Nations Educational, Scientific, and Cultural Organization. www.unesco.org.

2 - Decree 5.753-Promotes the Convention on the Safeguarding of Traditional Culture and Folklore. Fonte: http://www.planalto.gov.br/ccivil 03/ ato20042006/2006/decreto/d5753.htm. Retrieved on June 19, 2016.

3 - Hefesto - Character of Geek mythology. Sone of Zeus and Her. He was considered the God of technology, of the blacksmiths, artisans, sculptors, metals, metallurgy, fire, and volcanoes. Available at:

$\mathrm{http}: / /$ portalmitologico.blogspot.com.br/search?q=hefesto. Retrieved on April 11, 2016.
}

produces civilization and yet is capable of establishing a communitarian link.

The expression of "manual skill", according to Sennett (2015, p.19), deals "with the art or handcraft skill of making things well", a value that, according to him, disappears with the passage from society to the industrial era. Nevertheless, the author affirms that the handcraft skill is a "basic and permanent human impulse, the desire for quality work done by himself", which would negate its disappearance during the industrialization period with the advent of the machine.

In the Brazilian context, the definition of the craftsman, according to MDCI (Ministry of Industrial Development and Foreign Trade) (2012), is characterized as one of the richest forms of cultural expression and of creative power of a people, reaffirming their self-esteem and bringing with it questions of economy and social inclusion.

Crochet, within the classification of a handcrafted product, defined by the MDCI (2012), can be classified as a "traditional handcraft", as it consists of a set of cultural artefacts from a specific group, representing its traditions and everyday life.

The origins of crochet are uncertain. According to Ruthie Marks (1997), it may have begun in Arabia, spreading to the eastern regions of Tibet and to the western regions of Spain, where it followed the Arabian commercial routes to other countries of the Mediterranean. There are some indications that crochet came from South America, by a primitive tribe that uses crochet ornaments in rituals of puberty. There is also a third hypothesis that links its origins to the crochet dolls of China.

What we can affirm, however, is that it is a traditional knowledge that has accompanied the history of the women interviewed in this study and that was passed down by the matriarchs through family tradition. Crochet today is a knowledge that belongs to folklore, following the patterns created by the craftswomen themselves, and that has been incorporated within a wide range of fields, including design, architecture, and fashion.

According to Barroso (2001) one factor that adds value to handcrafts is that within it there are "cultural traces of the region of its origin", in addition to its "social function, which imparts dignity to those who produce it; in addition to being a source of the livelihood of those who work with it, it also brings the sense of self-esteem, of one's own pride, which is transformed into a spring toward the construction of citizenship" (BARROSO, 2001, p.6). On the same line, Keller (2014, p.331) points to handcrafts as a "differential product" and bearer of social identity, replete with a cultural load capable of awakening market interest. She also points out that handcrafts are products of "added value", which allow the craftswomen to supplement their own family income.

However, we cannot fail to mention one negative factor in the form of social relationships that are in constant growth in handcraft work, which is the exploitation of workers and the inhumane conditions that they have been submitted to, above all, with extremely 
low salaries. This fact occurs primarily in China, where, according to Ribeiro (2013) "its economic development, using enormous reserves of cheap labor as a 'comparative advantage', has converted the trade into a pole, quintessentially, of manufacturing production at the world level, considered to be the 'world's workshop', as it was called by England after the Industrial Revolution." Ribeiro further states that "the industry and all other sectors of the Chinese economy invest in technology and quality, yet it is difficult to compete with these products of low quality and price, as can be seen in China's mass exports".

\section{Methodology}

A social investigation is not a "succession of stereotypical methods and techniques that merely need to be applied exactly as they are presented" (QUIVY; CAMPENHOUDT, 2005 p. 18). These authors illustrate that in investigations in social sciences one must respect the processes according to each type of "specific investigation". They suggest that one must first make a core question, a "guiding line" for the study, which will break with the "precepts and prior notions" of the "scientific process", and this must provide the possible elements so that the question can be answered properly.
They make it explicit that in the scientific process: "the scientific fact is achieved, constructed, and verified." These three acts are rupture, construction, and verification (or experimentation).

After the core question has been posed, it becomes necessary "to translate these in a language and in forms that allow them to guide the systemic work of collection and analysis of observational and experimental data that must be followed" (QUIVY; CAMPENHOUDT, 2005 p.109). Through the model proposed by the authors, and based on the core question, a model of analysis was constructed to guide the study (Table 1).

Concerning action-research, Thiollent (2011), presents a type of empirical social study based on a strict partnership between the researchers and the participants.

This action-research method is present in this study in two main aspects. The first is due to the fact that the researcher is also a crocheter, and, for this reason, understands the entire process involved in the crochet knowhow. The second is due to the partnership that the researcher set up with part of the group of women interviewed in this study, with whom she has developed, over the past 6 years, pieces of clothing in crochet produced for her own line of apparel, Emerenciana, through which these pieces are being commercialized.

Table 1. Study analysis model.

\begin{tabular}{|c|c|c|c|}
\hline Concept & Dimensions & Components & Indicators \\
\hline \multirow{4}{*}{ Knowhow } & \multirow{2}{*}{ Intangible heritage } & Handcrafts & $\begin{array}{l}\text { - Generation of income/financial autonomy for the woman } \\
\text { - Strengthening of the group's identity / belonging / valuation } \\
\text { - Need for a craft fair to sell what is produced } \\
\text { - Manual production }\end{array}$ \\
\hline & & Tradition & $\begin{array}{l}\text { - Transmission of knowledge from generation to generation } \\
\text { - Maintenance of the craft }\end{array}$ \\
\hline & \multirow{2}{*}{ Group of women } & Feminine & $\begin{array}{l}\text { - The feminine figure linked to manual labor } \\
\text { - knowledge passed down by the women of the family or friends } \\
\text { of the family }\end{array}$ \\
\hline & & Meeting & $\begin{array}{l}\text { - Exchange of knowledge } \\
\text { - Specific group conversations } \\
\text { - Broaden their knowledge / improvements in their practice } \\
\text { - Virtual meeting via social networks }\end{array}$ \\
\hline
\end{tabular}

\section{Discussion}

\subsection{The interviews}

The technique of the semi-structured interview was adopted in an attempt to obtain elements and data corresponding to some of the indicators, defined in the study analysis model (Table 1).
This study interviewed 17 women who work with the crochet craft, from 17 to 84 years of age, from the cities of Campanha, MG and Três Corações, MG, Brazil. The study was developed over a 20-day period by means of visits to the homes of the interviewed women. To record the interview, recorders and cameras were used to register the speech and the images during the interviews, which were then transcribed to be exhibited in a scientific text. 


\subsubsection{The tradition and the feminine: The feminine figure in the transmission of the crochet craft}

The word tradition, according to MARTINS (1986, p.27), comes from the Latin trader, which means transference, passage. In this manner, the etymology of the term refers to transmission. Yet, according to the author, the term through a similar anthropological lens is associated with the notion of diffusion; however, he highlights that the difference between diffusion and tradition is that the former refers "to the transmission of the cultural load of a population" while the latter "operates in time", referring "to the transmission of cultural heritage from one generation to another within the same population". In this sense, crochet is traditional, because it exists even today in the day-to-day life of the women of the family.

The transmission of the crochet craft within the groups of crocheters is done exclusively by the feminine figure, that is, it is passed on, beginning in childhood, between 6 and 11 years of age, by the women of the family, including the mothers, aunts, grandmothers, or even a neighbor or close friend of the family.

I learned from my mother. An adept crocheter who used to keep the letters sent by the Greek ambassador, congratulating her for the beautiful dresses with silk thread. I've been doing crochet since I was 7. (Marlene).

During the visits, the women would take their private crochet collections, passed down by the family, from their drawers and their closets, pieces that had become treasures and that they stowed away with the highest of esteem. Each piece presented was a recollection of a story, some laughter, memories of their childhood, of their mothers, of their grandmothers, of life in the country, of meetings. Among the pieces were nightgowns (with the straps made of fine linen, which seemed even more like lace), embroidered towels with finely woven crochet beaks, blouses, bedspreads of various models and types of linen, pieces inherited from their grandmothers. Everything surrounded by a finesse that stretched far beyond the material object. The feelings, the memory, the identity, and the tradition of these women were all there.

My grandmother, at 100 years old, had already made 95 bedspreads, so I think I take after her. (...) I made laces for petticoats, combinations with spools of thread, and I made meters and meters, it was a fine linen. My aunts, grandmothers, greatgrandmothers, everyone did crochet, it was traditional to make wedding outfits for the daughters, granddaughters, it wasn't to make money, it was because we really liked it. (Shirley).

We can affirm just how strong the transmission of this trade is in this group. Teaching crochet is part of the tradition of these women, it is common and is part of the process to become a crocheter, to learn and to teach, and then to pass the trade on to others.
I used to teach in my house, I had 5 girls that I taught, 2 nieces and 3 friends. They would come to my house. We would meet in the large space in the doorway. (Paulina).

\subsubsection{The meeting}

Another factor always present in the interviewers' speech is the question of the meetings to do crochet, generally in the crocheters' homes. In this on-site meeting, there are exchanges of experiences, bolstering not only the transmission of the crochet trade, but also boosting social cohesion among these women, sharing stitches, modeling, conversations, snacks over coffee. They are good friends that are united toward the same end, doing crochet in a group of its own identity.

I meet with a group of friends. Almost every day, one goes to another's house, sometimes they come here, sometimes I go there. It's good, you know? Because one gets an idea from another, asks questions. (...) We talk about crochet, about what each one is doing. (Helena).

According to these crocheters, the meeting allows for the exchange, the transmission of the craft, and helps to maintain the friendship. It is a feminine meeting, guided by the conversation about everyday facts of a woman's life, of the household chores, and about crochet: the changing of stitches, of the models, of the novelties that they see on television, in the soap operas, on the internet.

\subsubsection{The virtual meeting}

We found that most of the crocheters get together to do crochet. This personal meeting, in the women's homes, will most likely continue to take place, as it is also part of the group's tradition. However, when we speak of meetings, we must also understand that these meetings repeatedly occurr in the "virtual" sphere in our everyday lives. In the case of these cocheters, this type of meeting occurs through the social networks, such as "facebook", "whatsapp", "pinterest", and "instagram", in the exchange of written messages, photos, stitching designs, and tutorial videos. The internet will be the mediator in the transmission of this knowledge, in such a way that the meeting passes from the on-site to the virtual sphere.

We share models, photos, videos, the learning is easy. On the internet we can learn a lot of things. (...) this type of virtual meeting is easier to take place, because getting together in person to do crochet is more difficult. (Ägueda).

In the current society, through the internet, the "virtual relationships" are more and more evident, illustrated by the quantity of access to courses, information, and exchanges made feasible by this instrument, making it possible that even the crafts considered to be traditional, as is the case of crochet, can be transmitted through the slant of the contemporary 
medias, walking hand in hand with the changes occurring in present-day society.

In this sense of change, "all of the cultural systems, even those traditional systems, are in a continuous process of change" (LARAIA, 1988, apud CASTRIOTA, 2009, p.22). Hence, there would be no "static culture", since the process of transmission is also linked to the changes absorbed by the other cultures, be they internal changes, changes made by the groups themselves, or even those coming from the contact with another cultural system. Therefore, the crochet ingrained in the tradition of the group of women would also go through changes, never leaving behind the memories of their matriarchs from past generations.

For these women, the internet opens new means to communicate with one another, regardless of distance or time. There, they also identify themselves as a group with its own identity, which is their common interest for crochet. There is the relationship of exchange, knowledge, friendship, confidence, as well as the place in which they exhibit and sell their pieces, be it for close friends, be it for distant people, around the world.

(...) Today, with modernity, an eye on the internet, always researching the trends of the seasons, I do a lot of research. (Marta).

And what was found in this group is that this new reality is seen in a positive light, as new opportunities arise for economic gains, while their field of knowledge also broadens through the access to videos, images, receipts, and even in the very exchange of knowledge among other women.

\subsubsection{The handcrafts: Economic factor and the desire to do crochet}

In this virtual meeting, in addition to the exchange of knowledge, there is also the economic factor, given that it consists of an opportunity to show their work and sell them to a large number of people. It can also be noted that the transmission of knowledge is more accessible, allowing for the diffusion and maintenance of the crochet craft. The economic factor, associated with the sale of the crocheted pieces also becomes important, since it constitutes an important complement to one's income, or even as the main source of income for the families of the interviewed crocheters'.

Their desire to do crochet appears in many senses: be it through an economic point of view, be it through one's own personal addiction to the trade, linked directly to the pleasure of doing, as well though the social meeting to do crochet linked to the transmission of knowhow and to the on-site or virtual meetings.

If I really had time, I would keep doing crochet. It is so good to get an order, take the string and sew $i t$, deliver it, and receive the money. We know the value we are going to make when we take on a job, plan what we're going to do with the money. (Dona Terezinha).
Within this question of the "desire to do", emotional and therapeutic aspects could be observed. This "desire to do" is confirmed, according to the crocheters, by the "addiction", pleasure, and beauty.

\section{Because I like it and it helps with my income, you know? But I think it's more because I like it. For me it's like a therapy, it calms me down. If you make love, with true desire, really like what you do (...) I love it when I see the finished piece, for me it's a pleasure, it's wonderful. (Angelina).}

\subsection{The partnership with the women crocheters: New view and new market for crochet}

Through action-research, this study also presents the partnership established between the researcher and some women from the group of crocheters. Through the Minas Gerais fashion apparel, Emerenciana, since 2009, a strict partnership has been built through the crochet craft in the production and sale of pieces, together with the meeting and exchange of knowledge, in turn better fostering their practices, the cohesion of the group, the maintenance of the tradition, and the source of family income, bringing with it the feeling of self-esteem and belonging to the group.

This partnership has brought a new field to these women, the market, which for them did not exist before. It also helped them to improve the production of pieces and even the quality of the product, in turn boosting sales while at the same time adding, together with the experience gained by each woman, new esthetic possibilities for their work. It brought another use for crocheting, as it suggested working with different models than those found in traditional crocheting (manually dyed) - a novel idea for the group of craftswomen who had been accustomed to working only with articles for the household.

For them, being inserted in the fashion world made it possible to augment the esthetic and experimental possibilities. It also served to foster greater income from the market in which the crochet became a product geared toward a differential public who has begun to understand the value of their handcrafted work through the producer and consumer relationship that this brand has been providing.

\section{Conclusion}

The study was developed from the perspective of how the traditional knowhow could add value to a group of crochet craftswomen, affirming and recognizing the construction of the individual and collective identities, through the lens of the intangible heritage.

The crocheter, when sewing, places her identity in each piece, her impression as a craftswoman, her experience of a life dedicated to the craft of crochet, typical characteristics of the manual work of an artisan. Upon valuing the work of the artisan, one also adds value to the product stemming from this knowhow, with 
possible positive repercussions for the development of the local economy.

It is also important to emphasize how the tradition adapts itself to the changes in society without getting lost in the shuffle. Crochet, as a traditional knowhow, located in the realm of Intangible Heritage or Folklore, has been transmitted and has been adapting to the contemporary means of communication in which they have become a positive instrument in the fomentation and maintenance of this group's craft.

Researching crochet and its valuation, therefore, reveals that the craft brings with it values that reach far beyond the crocheted pieces themselves, that is, beyond the final product. It stimulates the meeting of women, the conversations, the exchange of knowledge, the strengthening of identity, and the sustainability of the craft through the transmission and sale of the crochet pieces.

\section{Acknowledgements}

Acknowledgements to the CAPES - Coordenação de Aperfeiçoamento de Pessoal de Nível Superior for contributing with the resources to perform this research.

\section{References}

BARROSO NETO, Eduardo. O que é artesanato? Módulos 1 e 2. Revisão e editoração: Lucy Barroso. 2001

CASTRIOTA, Leonardo Barci. Patrimônio cultural: conceitos, políticas, instrumentos. São Paulo: Annablume, Belo Horizonte: IEDS, 2009.

HALL, Stuart. A identidade cultural na pósmodernidade. Tradução Tomaz Tadeu da Silva, Guaracira Lopes Louro. 10 ${ }^{\mathrm{a}}$ edição. Rio de Janeiro: DP\&A, 2005.

KELLER, Paulo F. O artesão e a economia do artesanato na sociedade contemporânea. Política \& Trabalho. Revista de Ciências Sociais, n. 41, Outubro de 2014, pp. 323-347

MARKS, Ruthie. History of crochet. 1997. Disponível em: $\quad$ http://www.crochet.org/?page=CrochetHistory. Acesso em 19/06/2016.

MARTINS, Saul. Folclore: Teoria e Método. Belo Horizonte. Imprensa Oficial. 1986.

QUIVY, Raymond; CAMPENHOUDT, Luc Van. Manual de Investigação em ciências sociais. Trajetos. Tradução: João Minhoto Marques, Marília Amália Mendes e Maria Carvalho. 4a edição. Editora Gradiva. Lisboa, 2005.

RIBEIRO, Renato Augusto. A China na economia internacional. In:

http://www.coladaweb.com/economia/a-china-naeconomia-internacional. Acesso em: 26/10/2015.

SENNETT, Richard. O Artifice. Rio de Janeiro: Editora Record. 2015. 5a edição.

THIOLLENT, Michel. Metodologia da Pesquisa-ação. 18a edição. Editora Cortez, 2011. 